\title{
Los derechos naturales entre Inquisición y Constitución
}

\section{Natural Rights among Spanish Inquisition and Constitution}

\author{
Enrique Álvarez Cora \\ Universidad de Murcia \\ eacora@um.es
}

Recibido: 03/06/2014

Aceptado: 15/12/2014

\section{Resumen}

El trabajo analiza la concepción racionalista de los derechos naturales, y las distintas tendencias que asume su discurso en la literatura prohibida por el Santo Oficio de la Inquisición, así como la evolución de su concepto, y los modos de interpretación jurídico-política, en el constitucionalismo español.

Palabras clave: Inquisición, derechos naturales, constitución.

\begin{abstract}
The paper analyses the rationalist conception of natural rights, and the differents trends that assumes its discourse in the Spanish Inquisition banned literature, as well as the evolution of its concept, and the juridical and political ways of interpretation in Spanish constitutionalism.

Keywords: Spanish Inquisition, natural laws, constitution.

Como es sabido, el Medievo y la Modernidad en España presentan un sistema político asentado en el iusnaturalismo teológico, fundamentalmente de raíz tomista. $\mathrm{La}$ existencia de Dios, y el deber que todo hombre tiene de seguirle, son creencias que impregnan cualquier reflexión epistemológica, la energía del orden social y de la estructura del poder. En términos jurídicos, el iusnaturalismo teológico significa que el Derecho divino se encuentra por encima de, informa e influye en el Derecho positivo,
\end{abstract}


en virtud de una relación jerárquica que se refleja, asimismo, en la pirámide que sitúa al rey como cabeza del reino, o a los estamentos nobiliario y eclesiástico, en su calidad privilegiada, sobre el resto de los hombres. La jerarquía política y social se ancla en el Ser Supremo - a partir de la teoría del vicariato, de la gracia de Dios que legitima al monarca- rector de la vida humana. Y decir esto, tan sintéticamente, aún es decir poco, puesto que el Derecho divino no sólo debe influir y predeterminar sustancialmente el Derecho positivo; también el Derecho natural ha de estrechar su naturaleza con el Derecho divino, someterse a él, y alimentarse de sus pautas morales. El Derecho natural, entre el Derecho positivo y el Derecho divino, no es un tronco que crezca desde la raíz del primero, sino una raíz que crece desde el tronco del segundo.

Este pensamiento vetusto y apodíctico sólo es puesto en duda, primero, por el protestantismo, y después, a rebufo, por la Ilustración. Se trata de un brote filosófico y libertino que, si cuaja en el siglo XVIII, alcanza consumación jurídica en los procesos constitucional y codificador del siglo XIX. En España, el cambio dinástico y las medidas borbónicas para la centralización política y administrativa abanderan un siglo de las Luces que, culturalmente, sigue viviendo en una Sombra señera. El país es un campo tradicionalista en el que las nuevas ideas filosóficas son cosa de minorías, y ni siquiera tanto por la creación original cuanto por la deuda que se tiene hacia la lectura de autores extranjeros, sobre todo franceses. Una reducida permeabilidad hacia el pensamiento racionalista explicable en no poca medida por la quintaesencia protestante -si no atea- que subyace en muchos de quienes rechazan el tradicionalismo iusnaturalista y por la veta subversiva y en cierto grado antimonárquica de sus postulados. En esta tesitura se entiende la virtud de una institución como el Santo Oficio, una Inquisición que dedicará sus esfuerzos, durante todo el siglo XVIII y el primer tercio del siglo xIX, a evitar la divulgación del pensamiento ilustrado y a cortar su irrefrenable circulación clandestina, tan minoritaria como copiosa. En efecto, el Santo Oficio de la Inquisición persigue y censura con denuedo la literatura extranjera de corte racionalista, revolucionario, antitradicional: controla la importación de libros en las aduanas, visita y registra las librerías y bibliotecas, califica en exámenes prolijos los contenidos de todo tipo de literatura -filosófica, política, histórica, religiosa, o meramente imaginativa-y prohíbe, en fin, con alcance público, la lectura o mera tenencia de cualquier género de letras considerado pernicioso.

Las ideas consideradas por el Santo Oficio impías, revolucionarias, sediciosas, si no heréticas, y dignas de que sus continentes fueran expurgados o -sobre todoprohibidos, son registradas por las censuras y resumidas pueden valer en calidad de fundamento del libertinaje filosófico o bien, por usar una expresión con mayor porte jurídico, del iusnaturalismo racionalista. Tales son ${ }^{1}$ :

\footnotetext{
${ }^{1}$ Extracto unas ideas cuyo desarrollo y localización concreta en expedientes inquisitoriales puede verse en mi trabajo "Iusnaturalismo racionalista y censura del Santo Oficio", en Enrique Gacto (ed.), Inquisición y censura. El acoso a la inteligencia en España, Madrid, Dykinson, 2006, pp. 233-281.
} 
a) La razón humana es la esencia del Derecho natural, porque la razón es un instrumento de conocimiento natural, o es la regla de conducta, en el hombre. Si el Derecho natural se define, entonces, por la razón humana, el hombre es libre, porque su propia razón lo rige. Y como la razón es común a todos los hombres, todos ellos son iguales. Igualdad y libertad se constituyen así en pilares de la nueva noción del Derecho natural racionalista. El Derecho natural racionalista, ya desde este momento, se transfigura en conjunto de derechos naturales.

b) Si el hombre se guía sólo por la razón que le es natural, la verdad revelada o el Derecho divino queda marginado. Dios no es preciso para la fundamentación del Derecho natural, cabe decir con moderación; o quizá, más radicalmente, Dios es tan sólo una posibilidad, una "inteligencia posible" que deriva del razonamiento humano. En ambos casos el Derecho divino no se sitúa jerárquicamente por sobre el Derecho natural. Podría decirse que el Derecho divino positivado mediante la Revelación deja de ser estrictamente sobre-natural. (Esto es lo que no admite el catolicismo riguroso: acepta que el Derecho natural se base en la razón, y el Divino en la revelación, pero nunca que se rompa, como quieren los racionalistas, la sumisión del primero al segundo.)

c) El fin que persigue el hombre es la felicidad. El Derecho natural, a través de la razón del hombre, ha de orientarse hacia la felicidad. Una felicidad pragmática, utilitaria, que tiene que ver con el buen ciudadano y la moral del "buen padre de familia" que enarbolará el Código civil napoleónico. Una felicidad como único principio moral de innata notoriedad en el hombre, a la manera de Locke.

d) Hay un iusnaturalismo racionalista anarcoide. Si el Derecho natural no empasta con el Derecho divino, la monarquía edificada por gracia de Dios comenzará a tambalearse. Además, en cuanto el gobierno haya sido injusto, el hombre tendrá derecho a la rebelión, a la subversión, en defensa de su libertad e igualdad que la jerarquía política y social y económica (monarquía, sociedad estamental, sistema económico de vinculaciones, etc.) yugula. En realidad, la guía del "uso libre de la razón" igual en todo hombre niega la existencia misma de la autoridad humana, de los códigos legales, de las instituciones sociales. La Anarquía ha de conducir a reavivar el contrato primigenio entre los hombres, o mundo de la razón, la libertad y la igualdad. Esto está inspirado en la lectura del Contrato Social de Rousseau. Por lo tanto, libertad e igualdad son "ideas eternas". Son, en fin, "derechos naturales" preexistentes, mutados o traducidos o doblados en otros como el derecho de seguridad individual o el de propiedad. Derechos naturales preexistentes y revolucionarios, porque su recuperación legitima todo levantamiento contra el poder político (y no derechos que el Estado ha de proteger y no vulnerar sin causa justa, como argumentan los censores del Santo Oficio, en la defensa de la jerarquía tradicional de poder). 
e) Hay un iusnaturalismo racionalista materialista. La distopía triunfa con algo más allá de la relativización del Derecho divino: no ya el espíritu arrinconado, sino el triunfo definitivo de la Carne. El alma racional, cuando toma relevancia, atenúa la pura humanidad, en el seno del mundo físico. Las diferencias entre hombres y animales se difuminan, e incluso entre los seres vivos y las cosas. ¿Conservan entendimiento los cadáveres? ¿Las piedras de la calle piensan? ¿Qué fino matiz distingue al ser humano del orangután? ¿Es realmente menor que la de una persona la inteligencia de un perro, de un delfín, de un elefante? ¿No nació el hombre de una fermentación de moléculas, como los rábanos o los puerros? ¿No es cierto que la materia es eterna, y que en el universo no hay ni creación ni aniquilación, sino transformación tan sólo? ¿No es exacto que el mundo no es sino una combinación de átomos? Dios es sólo una Máquina del Mundo, o no existe.

f) Cuando no deviene ateísmo materialista, el racionalismo postula una "religión natural", pero esta religión natural se traduce, mejor, en una Moral Universal. Moral una, curiosamente frente al protestantismo disperso que permitió el germen de sus ideas. Moral universal, con pretensión de sustituir la universalidad católica. La obra de Paul Henri Dietrich Holbach que expedientó el Tribunal de la Inquisición de Barcelona -como expedientó su traducción al español el Tribunal de la Inquisición de Corte--, publicada en Amsterdam en 1776, llevaba por título precisamente La Moral Universal. Y fijémonos en el subtítulo: los deberes del hombre fundados en su naturaleza. Esa pluralidad de derechos naturales, en los que se desgajó el viejo, uno y subdivino Derecho natural, integradores ahora de la enardecida y a contramano Moral única y natural y racional.

Claro es que las seis bases del iusnaturalismo racionalista que acabo de comentar aparecen entreveradas en los libros y folletos que el Santo Oficio escudriña. Valga como ejemplo la censura de la Nueva Encyclopedia Methodica, capturada en su versión francesa, y cuyo artículo "Nature" en la voz "Jurisprudencia" (tomo 6, primera parte) da lugar a reflexiones sobre el cúmulo conceptual racionalista por parte de los calificadores que ejercen a la orden del Consejo de la Suprema. Así, fray Antonio de la Santísima Trinidad, en la calificación que firma en Madrid a 2 de noviembre de 1788, explica que los "nuevos filósofos libertinos niegan las verdades reveladas de la Escritura". Defienden, en su error impío, que la naturaleza es un estado de perfecta libertad para el hombre, desprendido de cualquier dependencia de ajena voluntad, tanto en la esfera individual, cuanto en la esfera colectiva: el hombre es un sujeto con libre disposición de la propia persona, y de los propios bienes, por una parte; $\mathrm{y}$, por otra, el hombre pertenece a un estado de igualdad que únicamente reconoce poder y jurisdicción si viene a resultar recíproco entre sus semejantes. En conclusión, los filósofos hacen caso omiso - dice el censor-del hecho verdadero de que no haya 
habido más estados, conforme a la ortodoxia católica, que el estado de inocencia y el estado de culpa original; y no reconocen, si no es en el pacto social frente a la tiranía, el origen de las potestades supremas, espiritual y civil. Una segunda calificación, firmada por fray Tomás Muñoz en Madrid, a 22 de enero de 1790, reprueba la concepción del estado de naturaleza como estado de perfecta libertad en el que el hombre se muestra independiente de las leyes civiles, políticas, económicas y criminales, y aun de las leyes divinas y principios revelados. Esos poder y jurisdicción mutua y recíproca, sin subordinación de unos hombres a otros, "tal vez" son la Anarquía, por la que suspiran los "falsos filósofos" empeñados en sostener los que llaman "derechos inenajenables de la humanidad, y de la naturaleza". El 30 de abril de 1799 Muñoz firma, con otros, una nueva censura, en la que destaca cómo el nombre de Rousseau no se pronuncia jamás en la obra sin un profundo respeto, y cómo las leyes civiles y "aun las fundamentales" del cuerpo político no encuentran apoyo en los filósofos ${ }^{2}$.

Los filósofos no respetan ni las leyes civiles ni las leyes fundamentales -espetaba el cacumen inquisitorial-. Liquidan a cercén las leyes fundamentales que son las leyes tradicionales del sistema político basadas en el iusnaturalismo teológico. Desprecian esas leyes fundamentales que el moderantismo pretenderá mantener subterráneamente en el alumbramiento de la fuente primordial del Estado liberal de Derecho: la Constitución. Lo que me preocupa ahora es aproximarme al momento en el que la concepción de los derechos naturales preexistentes elaborada por el iusnaturalismo racionalista cuaja como desiderátum normativo: lo que durante el siglo XVIII había sido una renovación filosófica foránea, errónea y clandestina del pensamiento tradicional, aflora como materia jurídica en los proyectos constitucionales que se suceden durante los siglos XIX y XX. ¿Con qué peso, y con qué planteamientos rivales?

1. Derechos naturales conforme a los principios del Derecho divino. Desde luego, la consideración de un Derecho natural subdivino se descarta en el sistema constitucional decimonónico. Algún amago, de calado tradicionalista y caduco, puede encontrarse, mas a finales del siglo XVIII, en el proyecto de Constitución de 1794-1795, de León de Arroyal. El autor sabe perfectamente que está componiendo un texto en escenario de iusnaturalismo racionalista pujante. Por eso reconoce - para salvar el rótulo constitucional que pretende atribuir a su programa- en primer lugar que todos los hombres "son hijos de un padre y nacen iguales por naturaleza"; en segundo lugar que "sólo las virtudes o los vicios los deben distinguir en la sociedad"; y en tercer lugar que el fin de toda sociedad "es la felicidad de los hombres" cuya garantía sólo puede lograrse "por el pacto social". La utilización de los conceptos racionalistas-igualdad, felicidad,

\footnotetext{
${ }^{2}$ Archivo Histórico Nacional (= AHN), Inquisición, leg. 4481 n. 15.
} 
pacto social: aunque su interpretación desde la ortodoxia católica no quede excluidaes tan evidente, y casi chocante si no se concibiera como una fórmula antibiótica que pretende corromper la entraña de su mecanismo. León de Arroyal, al fin, descubre con toda claridad sus cartas, al decir que el pacto social garante de felicidades e igualdades "en tanto es válido es cuanto se conforma con los principios de la Ley eterna", es decir, "el orden admirable que Dios puso en el universo"3. Así aparece, salido de la baceta, el Derecho natural subdivino.

2. Derechos legítimos constitucionalizados. Artilugios de este último calado no serán posibles, empero, a partir del advenimiento del Estado liberal que se levanta en contra y de la mano, a la sazón, de la invasión napoleónica. Ahora bien, la Constitución de 1812, como resultado primero y manifestación inauguradora del nuevo sistema político, afrontará la contemplación de los derechos naturales de una forma que no puede tampoco vincularse a la descripción de los derechos naturales preexistentes propia del iusnaturalismo racionalista.

La Constitución de 1812 dice en su artículo 4 que

“La Nación está obligada á conservar y proteger por leyes sabias y justas la libertad civil, la propiedad, y los demas derechos legítimos de todos los individuos que la componen"4.

Los derechos que la filosofía racionalista consideraba naturales -libertad, propiedad- no son tales, sino "derechos legítimos", y su conservación y protección se encomienda a la ley. Hay, pues, un fenómeno de positivación de derechos en este texto. La Constitución -o la ley- es la que conserva y protege derechos que, en cuanto "legítimos", remiten en su naturaleza, a su vez, a la legalidad. Los derechos aparecen legalizados o, en cuanto encuentran su referencia última en la protección constitucional, constitucionalizados. Se trata, pues, de derechos constitucionales, y no de derechos naturales; de derechos que la Constitución o la ley positivan, y no de derechos que preexistan.

La reticencia de la Constitución gaditana a mostrar una línea de argumentación que supure un tono afrancesado puede ser una razón de esta distancia respecto del racionalismo. Sería la misma explicación que afecta a la falta de una declaración de

\footnotetext{
${ }^{3}$ Ignacio Fernández Sarasola, Proyectos constitucionales en España (1786-1824), Madrid, Centro de Estudios Políticos y Constitucionales, 2004, núm. 1-4, p. 20.

${ }^{4}$ Raquel Rico Linage, Constituciones históricas. Ediciones oficiales, Sevilla, Universidad de Sevilla, 1994, p. 20.
} 
derechos semejante a la de $1789^{5}$. Puede parecer una precaución de pura apariencia, pero ahí está. Desde luego, una interpretación de derechos constitucionales frente a derechos naturales no es una concepción improvisada. En su Constitución de 1809 Álvaro Flórez Estrada conoce perfectamente que el constitucionalismo ha encontrado su catapulta en el iusnaturalismo racionalista, con los derechos naturales preexistentes que él llama "imprescriptibles" e "inenajenables" . Pero termina dotando de sobrevalor a su constitucionalización:

\begin{abstract}
"Es, pues, utilísimo, o por mejor decir forzoso, que los derechos del ciudadano y los deberes de los depositarios de la autoridad pública estén expresados y designados de un modo claro, sencillo e inteligible a todos. La declaración de estos derechos y deberes es absolutamente necesaria; sin ella los más de los individuos que componen la sociedad, por más claros y evidentes que sean, los ignorarían completamente y los expondrían, como ha sucedido hasta aquí, a ser víctimas del error y de la tiranía"8.
\end{abstract}

\footnotetext{
${ }^{5}$ Veamos un caso, no jurídico, pero que da buena cuenta de esta reticencia hacia lo francés. El Catecismo para el uso de todas las Yglesias del Ymperio francés mandado publicar por el Emperador Napoleón, traducido al castellano e impreso en Madrid por Villalpando en 1807, es objeto, en el expediente del Tribunal de la Inquisición de Zaragoza, de dos censuras, en 1816, en las que se destaca, al margen de cuestiones teológicas, el hecho de que se trate de un catecismo publicado por la autoridad civil para todas las iglesias católicas del Imperio, con lo que esto denota de tiranía sobre y humillación de la autoridad de la Iglesia. A la vista de las calificaciones, el inquisidor fiscal aboga por la expurgación. Pero en la censura que ordena, a su vez por orden del Consejo, el Tribunal de la Inquisición de Corte, elaborada por fray Joseph del Salvador en 1817, se dice que aunque repele que venga de Napoleón, el contenido es doctrina sana. Fray Juan de Algora y fray Bernardo de San Agustín en 29 de julio de 1817 firman que "a los primeros censores o les faltó el tiempo, o les sobró el mal humor, y horror natural a que en España se admite un catecismo francés, teniéndolos nosotros tan buenos"; basta, pues, con quitar las adulaciones al tirano y el decreto. En AHN, Inquisición, leg. 4468 n. 15.

${ }^{6}$ De las proposiciones contenidas en el Catecismo político arreglado a la constitución de la Monarquía española por D. J. C. Palma (por Miguel Domingo, 1812), expedientado por el Tribunal de la Inquisición de Barcelona, se deduce que la Constitución de 1812 copia los principios revolucionarios y democráticos de la Constitución francesa de 1791, anticristiana y antipolítica. La potestad legislativa no reside sólo en el rey, sino en la nación con su monarca, o no en el solo monarca independiente (se dice también) sino en la nación: luego -como afirma la censura de fray Jaime Soler en 1815- la ley promulgada por el monarca no tendrá fuerza de ley hasta que el pueblo la reciba. La soberanía -se añade- reside en el pueblo, y el soberano, como los demás ciudadanos, recibe la autoridad de la nación; la libertad y la igualdad -reprueba la siguiente calificación- son los derechos de los españoles. En AHN, Inquisición, leg. 4469 n. 27.

${ }^{7}$ Fernández Sarasola, op. cit., p. 101: "Establecida esta verdad como un principio de que no puede dudarse, se deduce claramente que ningún asociado puede desprenderse de aquellos bienes sin los cuales no le resultaría esta felicidad; y si hubiese un pueblo tan imbécil que se hubiese privado de los primeros derechos que la naturaleza ha ligado a su ser, sus descendientes no estarán obligados a sufrir una ley tan dura que se opone al derecho natural. / Estos bienes, que llamaré imprescriptibles e inajenables, los reduciré a tres, a saber: la seguridad, la libertad y la igualdad de condiciones".
}

${ }^{8}$ Ibidem, p. 92. 


\section{Los derechos naturales sólo lo son gracias a la Constitución:}

"Sin constitución no hay libertad. La constitución es la que establece y asegura los derechos de los pueblos".

El último apartado de la Constitución de Flórez Estrada se titula "De los derechos que la constitución declara pertenecer a todo ciudadano y de los que ella les concede". Parece claro que este temprano texto -anterior por poco tiempo a la Constitución de 1812- se mueve con esa orientación advertida de los derechos constitucionales. Acoge una opción técnica contemporánea contemporizadora ${ }^{10}$.

3. Derechos naturales imprescriptibles y supraconstitucionales. Por lo tanto, el constitucionalismo no se inaugura vinculado al iusnaturalismo racionalista por lo que se refiere a la configuración de los derechos y libertades. Se aleja de una concepción de los derechos naturales preexistentes y superiores propia del iusracionalismo que, de haberse elegido, ofrecía un discurso muy claro. Así se comprueba en algunos otros ejemplos del género literario de la constitución. En las Instrucciones para la constitución de 1810 de José María Peinado, aunque el tono constitucionalizador de la Constitución de 1812 también está presente -bajo la expresión más matizable (entre derechos constitucionales y derechos naturales) de "derechos del ciudadano" 11 el subrayado de la igualdad, la propiedad, la seguridad y la libertad como "derechos naturales e imprescriptibles" queda rotunda cuando se añade que la "justicia natural se viola cuando una parte de la nación pretende privar a la otra del uso de sus derechos

\footnotetext{
${ }^{9}$ Ibidem, p. 98.

${ }^{10} \mathrm{El}$ Catecismo político sentencioso o doctrina del buen ciudadano amante de su religión, de su patria $y$ de su rey (impreso en Madrid y reimpreso en Zaragoza en la imprenta de Andrés Sebastián, 1814) sufre la prohibición "in totum" por el Tribunal de la Inquisición de Zaragoza que confirma el Consejo de la Suprema para el primer edicto (que será de 1817). La censura de los calificadores Ignacio Foncillas y Vicente Barta, en 1815, señala como idea reprobable, que huele a ateísmo y deísmo, la defensa de que el ciudadano haya de perseguir el fin de servir a la patria y buscar honras y privilegios: esta pauta de conducta $-\mathrm{y}$ aquí viene lo peor- excluye un fin sobrenatural, niega que Dios sea el fin del hombre. En consecuencia, el Derecho divino queda carente de supremacía. Pero el catecismo no extrae la consecuencia de derechos naturales desligados de la divinidad, sino que prefiere elevar a los altares a la propia Constitución (la de 1812, claro, abolida entonces por Fernando VII), como "buena, justa, sabia y equitativa, principio de todos los bienes y fin dichoso de todos los males". En AHN, Inquisición, leg. 4489 n. 11.

${ }^{11}$ Fernández Sarasola, op. cit., p. 167: "y la nación española que hoy reunida en Cortes ha recobrado la antigua dignidad del hombre, conociendo que los males espantosos en que ha sido sumergida, y que por tantos siglos la han agobiado, nacen del olvido de tan sagrados principios, de la ignorancia de los derechos del ciudadano, y del abuso del poder; hace la declaración solemne de ellos, señala los límites de sus obligaciones, los de las autoridades, los de la ley, y establece la constitución sólida permanente e inviolable".
} 
de propiedad, libertad y seguridad"12. Absolutamente tajante, la anónima Constitución Fundamental de los Libertadores del Género Humano (1810-1814), declara:

“ $\mathrm{OH}$, hombres bienaventurados que lograsteis gozar de la ilimitada libertad con que nacemos todos, y que es uno de nuestros más imprescriptibles derechos; que pudisteis disfrutar de todos cuantos frutos os producía la tierra; que no conocisteis Reyes ni Sacerdotes que atasen vuestra libertad, os comiesen el fruto de vuestros trabajos y sudores, y os sacrificasen a su antojo de todas las maneras"13.

Y amén de dar mandobles al Santo Oficio ${ }^{14}$, insiste en el "derecho imprescriptible de igualdad con que nacemos todos"15.

Sin embargo, una sola constitución vigente asume el iusnaturalismo racionalista; y, en este sentido, se gusta radical y revolucionaria, de raíz anarcoide. Se trata de la Constitución de 1869. En dos artículos se condensa esta posición. El artículo 22 reza:

"No se establecerá ni por las leyes ni por las Autoridades disposicion alguna preventiva que se refiera al ejercicio de los derechos definidos en este título"16.

El artículo 29 añade:

"La enumeración de los derechos consignados en este título no implica la prohibición de cualquiera otro no consignado expresamente" ${ }^{" 17}$.

Evidentemente, la concepción de unos derechos naturales anteriores, superiores a la legalidad y al propio texto constitucional, queda paladinamente expresada.

En todo caso, la Constitución de 1869 no llega a ser tan tajante como el texto que mejor define la vocación iusnaturalista racionalista: el proyecto de Constitución de 1873 de la I República. Su artículo 21, por una parte, reitera los términos del artículo 29 de la constitución democrática ${ }^{18}$; por otra parte, el título preliminar deja todavía más claro, como pórtico, cuál es su orientación, su convicción:

\footnotetext{
${ }^{12}$ Ibidem, arts. 3-4 y 7, p. 168.

${ }^{13}$ Ibidem, p. 687.

${ }^{14}$ Ibidem, artículo 25, p. 695: "El horrendo Tribunal de la Inquisición es el primer blanco contra que deben dirigirse todos nuestros escritores, y la Convención debe emplear todos sus esfuerzos para abolirle, como es el apoyo más firme de los déspotas".

${ }^{15}$ Ibidem, artículo 39, p. 697.

${ }^{16}$ Rico Linage, op. cit., p. 142.

${ }^{17}$ Ibidem, p. 142.

${ }^{18}$ Diego Sevilla Andrés, Constituciones y otras Leyes y Proyectos Políticos de España, Madrid, Editora Nacional, 1969, I, p. 561: "No se establecerá, ni por las leyes ni por autoridades, disposición alguna preventiva que se refiera al ejercicio de los derechos definidos en este artículo".
} 
“Toda persona encuentra asegurados en la República, sin que ningún poder tenga facultades para cohibirlos, ni ley ninguna autoridad para mermarlos, todos los derechos naturales. (...) Estos derechos son anteriores y superiores a toda legislación positiva"19.

4. Razones de la constitucionalización preternaturalista de los derechos, y perspectivas historicista y normativista. Así las cosas, la frustración que para el iusnaturalismo racionalista supone su asunción sólo excepcional en los textos constitucionales tiene que explicarse por algún motivo. Para entender cuál es la corriente de pensamiento jurídico que está influyendo en esta constitucionalización diríamos preternaturalista del sistema (con arranque dubitativo en la Constitución de 1812) puede ser interesante acudir a las discusiones doctrinales de finales de siglo. Y elijo con este fin un debate, primero, en sede parlamentaria, proclive no sólo a razonamientos filosófico-jurídicos sino a la subsunción de tales razonamientos en actividad legislativa; segundo, a propósito ya no de constituciones, sino del Código civil, con lo que afecta al derecho - de propiedad- que como ningún otro identifica las pretensiones políticas de la burguesía motora del Estado liberal de Derecho; y tercero, centrándome en la intervención de un diputado conservador regeneracionista, del que no cabe esperar un sesgo político ni radical ni sorprendente ni singular. Me refiero a la exposición del diputado Ramón Fernández Hontoria en la sesión del Congreso de los Diputados de 11 de junio de 1885.

El punto de partida de sus consideraciones se halla en la aceptación de un pensamiento jurídico que concibe sólo un Derecho natural integrado o tendente a la positividad. En el seno de éste, como es sabido, late potencialmente un positivismo de cuño francés y un historicismo de cuño alemán que tienen en común la pretensión de ir más allá que el iusnaturalismo racionalista (cuyo atrevimiento hizo posible al fin y al cabo el suyo) en cuanto no se limitan a trastornar la sustancia del Derecho natural sino que prefieren excluir su posición prevalente sobre el Derecho positivo. El camino lo marca la filosofía de un autor cuyo pensamiento -susceptible de interpretaciones políticas muy distantes- goza de un prestigio general en Europa. Es Hegel, a quien glosa Fernández Hontoria ${ }^{20}$ :

"Todo lo racional es real; todo lo real es racional", lo cual quiere decir, segun el mismo Hegel lo indica (por más que despues sus discípulos hayan desnaturalizado la idea), que hasta el último pormenor, que hasta el detalle más insignificante de la realidad es conforme á lo ideal, á lo justo, es determinacion del principio eterno, absoluto, ya que el individuo no obra sino conforme á su esencia, que es la del ser absoluto é ideal, segun los tiempos y las circunstancias, para llegar en una escala

\footnotetext{
${ }^{19}$ Ibidem, I, p. 558.

${ }^{20}$ Diario de Sesiones de Córtes. Congreso de los Diputados. Legislatura de 1884-85, Madrid, Imprenta y Fundición de los Hijos de J. A. García, 1885, tomo X, núm. 170, p. 4930.
} 
ascendente á su total y magnífico desenvolvimiento Desaparece, pues, ese órden inasequible que se presentaba como una meta nunca abordable y siempre presente. Lejos de eso, aparece confundido con la realidad, y por eso dice Hegel que el derecho natural y el derecho positivo son una misma cosa".

Y el diputado continúa después, tras anunciar que "esta escuela vino á coincidir en las consecuencias con la escuela histórica":

"Derecho natural es en esta escuela el enunciado en la conciencia humana para todo tiempo, para todo lugar, para todo evento: derecho positivo es, como el nombre indica, el derecho puesto (positum) en la vida, aplicado á cada relacion particular en el tiempo y en las circunstancias especiales que la determinan. De suerte que no debe haber contradiccion entre los dos términos, sino que el derecho positivo ha de ser el mismo derecho natural aplicado en el tiempo, aplicado á cada relacion, penetrando la trama entera de la variedad de las relaciones jurídicas positivas. En tal concepto, no aparece aquel derecho como un sueño de la fantasía ó una esperanza irrealizable, ni tampoco la injusticia como necesaria en el mundo; antes se afirma que el derecho natural es por su propia naturaleza asequible, factible, realizable, y que el órgano de esa manifestación en la vida es el derecho positivo, el cual, si bien en la práctica puede separarse ó contradecir al primero por ignorancia ó torcida voluntad, no es necesariamente injusto ni es razon el que alguna vez lo sea".

\section{La conclusión es clara:}

"Es decir, señores, que hoy ya no cabe confusion ni engaño en este punto, y que por tanto la base de las leyes y los Códigos ha de ser única y exclusivamente el derecho, lo que afirmamos que es derecho".

El Derecho natural resta devorado por el Derecho positivo. Entonces, Fernández Hontoria, basándose en la distinción de Ihering entre el "sistema de la libertad" y el "sistema de la coacción""21, explica que de acuerdo con el primero

“el pueblo debe gobernarse á sí mismo, debe darse sus leyes, debe proveer á su gobierno y administracion, y debe administrarse justicia, y que al propio tiempo tiene la mision de realizar él mismo, espontáneamente, sus fines, y de ahí las llamadas libertades necesarias ó derechos individuales (...) ¿qué significa más que el principio de libertad informando la vida política, de manera que el derecho se produzca

\footnotetext{
${ }^{21}$ Ibidem, núm. 170, p. 4931. En la sesión de 12 de junio de 1885, Fernández Hontoria identifica el "sistema de la libertad" con Inglaterra, y el "sistema de la coacción" con Francia, el "sistema de la coacción" con Castilla, y el "sistema de la libertad" con Cataluña, Aragón, Navarra y Vizcaya: ibidem, núm. 171, p. 4975.
} 
directamente por el pueblo, limitando el Estado su intervencion únicamente á dar las condiciones necesarias para que ese resultado se produzca?"

Y este liberalismo (como la positivación de Hegel) vale tanto para escuelas conservadoras cuanto para escuelas radicales:

“¿Y dónde está la distincion? Todo el problema que discuten está en si esa libertad puede y debe darse de pronto y de golpe, ó si, por el contrario, debe ir acomodándose al estado del país, á las costumbres establecidas, á la cultura jurídica, para que subsista sin menoscabo del órden social"'22.

Por el contrario, en el "sistema de la coacción", "la legislacion y el Gobierno ejecutan ellos mismos el trabajo: buscan por medio de la ley y de la coaccion el alcanzar los fines de que se trata". Aunque el diputado identifica este sistema con el Antiguo Régimen, fácilmente se adivina que lo hace de una forma meramente especulativa, o si se quiere programática (frente al intervencionismo estatal, sobre todo económico), pero falaz en sustancia, porque el ejercicio del poder estatal y la utilización del arma de la ley son con evidencia irrenunciables también para el liberalismo, máxime desde una perspectiva de positivación del sistema. Sería mejor decir que el "método coactivo" permanece, aunque desde una fundamentación normativa o Estado de Derecho que se define por su persecución de la libertad, mas a su vez desde esa doble óptica conservadora o radical, historicista o puramente positivista en fin.

Historicismo o positivismo son, pues, caminos para un sistema constitucionalizado, y por lo tanto de derechos constitucionales. Y, ciertamente, las constituciones adoptan una opción u otra, con la salvedad de la anodina en este sentido Constitución de 1837.

Una evidente perspectiva conservadora o historicista es la asumida por la Constitución de 1845:

"Que siendo nuestra voluntad y la de las Córtes del Reino regularizar y poner en consonancia con las necesidades actuales del Estado los antiguos fueros y libertades de estos Reinos (...)"23.

En una línea que en realidad también puede registrarse desde principios de siglo $^{24}$. Y que alcanza a la Constitución de 1876, cuyo artículo 14 dice:

\footnotetext{
${ }^{22}$ En la sesión de 12 de junio, Fernández Hontoria se declara liberal conservador: ibidem, núm. 171, p. 4975.

${ }^{23}$ Rico Linage, op. cit., p. 113.

${ }^{24}$ Así, las insinuaciones sobre las Cortes de 1809 de John Allen rezan: "Pero no habiendo extrema necesidad ni obligación urgente de destruir antiguos privilegios, es más conveniente modificarlos y conservarlos, que suprimirlos y abolirlos: especialmente en la infancia, o restablecimiento de un Gobierno
} 
"Las leyes dictarán las reglas oportunas para asegurar á los españoles en el respeto recíproco de los derechos que este título les reconoce, sin menoscabo de los derechos de la Nacion, ni de los atributos esenciales del poder público"25.

Si el sometimiento a la tradición era más crudo en la Constitución de 1845, en la Constitución de 1876 se encauza a través de una fórmula políticamente de tono menos añejo: los "derechos de la nación" y los "atributos esenciales del poder público" son condicionamientos - en palabras citadas de Fernández Hontoria- "á las costumbres establecidas, á la cultura jurídica, para que subsista sin menoscabo del órden social". Tradición y orden -y no exactamente derecho antiguo- limitan el respeto de los “derechos". ¿Qué derechos? Aquéllos que el título constitucional reconoce. Los cuales pueden incluso catalogarse de forma similar a como lo hacía la iusnaturalista racionalista Constitución de 1869, una vez alterada, esto sí, la cláusula interpretativa de referencia.

La perspectiva positivista o normativista tiene una manifestación más tardía. Y tiene que ver con un pensamiento filosófico que, si bien abierto por Hegel (en cuanto subsumió el Derecho natural en el Derecho positivo), da frutos jurídicos suficientemente singulares, excluyentes del Derecho natural y potenciadores en extremo de la positivación formalista y jerárquica, en la figura de Kelsen. Él es el inspirador de la Constitución austríaca de 1920. Pues bien, el proyecto de Constitución de 1929, en tiempo de dictadura primorriverista, asume un postulado de normativismo hasta ahora inédito en el constitucionalismo español. Es verdad que el Proyecto recoge en su artículo 30 la manifestación conservadora del artículo 14 de la Constitución de 1876:

"Las leyes dictarán las reglas oportunas para asegurar a los españoles en el respeto recíproco de sus derechos, sin menoscabo de los de la Nación, ni de los atributos esenciales del Poder público"26.

Pero del mismo modo que esta cláusula interpretativa de los derechos constitucionales trastorna la comprensión del catálogo de derechos básicamente conforme con la Constitución de 1869 (sujetos en ésta a su propia cláusula de preexistencia y superioridad natural), funge a la sazón complementaria de la regla fundamental que la constitucionalización del sistema asume en el artículo 102:

\footnotetext{
libre", "la abolición de ancianas costumbres, derechos, o inmunidades destruye el respeto y veneración a las instituciones antiguas; y la principal política de los amigos de la libertad, en el momento de restaurar un gobierno libre, caído en desuso, debe consistir en fomentarlas e imprimirlas en la mente del público". En Fernández Sarasola, op. cit., p. 621.

${ }^{25}$ Rico Linage, op. cit., p. 165.

${ }^{26}$ Sevilla Andrés, op. cit., II, p. 28.
} 
"La Constitución, como estatuto fundamental de la Monarquía, está garantida en la forma siguiente: / $1 .^{\circ}$ Tiene jerarquía superior a las demás leyes y a las decisiones de los diferentes Poderes. / 2. ${ }^{\circ}$ Dichas leyes y decisiones se deberán acomodar a la Constitución, y no podrán derogarla ni modificarla, directamente ni por vía de interpretación" ${ }^{27}$.

La constitucionalización de derechos se ha apuntalado en la supremacía jerárquica constitucional. Por eso el conservadurismo del texto precisa de la cláusula interpretativa de la Constitución de 1876: para frenar la superioridad de los derechos en la que la supremacía jerárquica de la Constitución deriva mediante su limitación material política intraconstitucional.

Precisamente la falta de una disposición que imponga la supremacía formal de la Constitución en el sistema jurídico provoca dudas sobre la eficacia de la Constitución de 1931 en orden a la salvaguarda de un catálogo de derechos que resulta verdaderamente minucioso. El texto se meve sin duda en la línea del normativismo, como demuestra la vocación garantista de su articulado: el título III se titula "Derechos y deberes de los españoles" y su capítulo primero "Garantías individuales y políticas" 28 . No obstante, la propia amplitud del catálogo de derechos da la impresión de una preocupación por el mundo de las libertades antes material que formal, y sin que este criterio material se acompañe de naturalismo racionalista ninguno, ni de referente otro de naturaleza que explique su orientación; la influencia socialista de los preceptos no se traduce, desde este enfoque, en ningún criterio jurídico de consideración técnica de derechos. Mas de la vocación material por sobre formal da ejemplo el artículo 25, toda una declaración del derecho y libertad primero entre pares, del derecho "jerárquicamente superior" a todos los derechos, la nuez de un sistema de libertades individuales:

"No podrán ser fundamento de privilegio jurídico: la naturaleza, la filiación, el sexo, la clase social, la riquezas, las ideas políticas ni las creencias religiosas"29.

Sin embargo, el vehículo formal garantista de estos derechos y libertades materialmente realzados no es, como ya se ha dicho, el propio texto constitucional con declaración de supremacía; lo es, antes bien, la institución del Tribunal de Garantías Constitucionales. No se evita así, a la postre, que esta solución parezca poco garantista en puridad, o conservadora en cuanto aislada, porque si la remisión a un ámbito de decisión propio como el del Tribunal no se complementa con la sumisión formal de éste ni a Constitución normativa ni a derechos naturales preexistentes, las

\footnotetext{
${ }^{27}$ Ibidem, II, p. 53.

${ }^{28}$ Rico Linage, op. cit., p. 220.

${ }^{29}$ Ibidem, p. 220.
} 
interpretaciones cuando menos historicistas del catálogo de derechos quedan posibilitadas.

5. Sincretismo constitucional. Con esta panorámica, la Constitución de 1978 resulta mucho más perfecta. El empaque material de los derechos -lo mejor de la Constitución de 1931- está presente en el básico y fundamental artículo 14:

"Los españoles son iguales ante la ley, sin que pueda prevalecer discriminación alguna por razón de nacimiento, raza, sexo, religión, opinión o cualquier otra condición o circunstancia personal o social”.

El texto ofrece también un amplio catálogo: distingue en el capítulo II del título I "De los derechos fundamentales y de las libertades públicas" en la sección primera, y "De los derechos y deberes de los ciudadanos" en la sección segunda. Y la vocación garantista se pone de relieve en el rótulo del capítulo IV del título I, "De las garantías de las libertades y derechos fundamentales", así como en el Tribunal Constitucional. Pero la actividad de éste se enmarca en una comprensión redonda del valor de la Constitución y de los derechos. Según el artículo 9.1:

"Los ciudadanos y los poderes públicos están sujetos a la Constitución y al resto del ordenamiento jurídico".

Lo que deja clara la supremacía constitucional normativista, aunque no de forma tan palmaria como en el proyecto de 1929. Además, hay un influjo, o un sabor a iusnaturalismo racionalista en la consideración de una especie de derechos naturales imprescriptibles, a saber, primero, los "valores superiores del ordenamiento jurídico" citados en el artículo 1.1:

“España se constituye en un Estado social y democrático de Derecho, que propugna como valores superiores de su ordenamiento jurídico, la libertad, la justicia, la igualdad y el pluralismo político".

Y segundo, los “derechos inviolables" e "inherentes" de la persona humana -más nítidamente supraconstitucionales que los valores superiores del ordenamiento jurídico- como "fundamento del orden político" conforme al artículo 10.1:

"La dignidad de la persona, los derechos inviolables que le son inherentes, el libre desarrollo de la personalidad, el respeto a la ley y a los derechos de los demás son fundamento del orden político y de la paz social". 
Por lo tanto, la Constitución de 1978 consolida la jerarquía normativa de la Constitución, elimina los límites intraconstitucionales de los derechos (presentes en la Constitución de 1876 y en el proyecto constitucional de 1929), asume una prolija catalogación material con el subrayado de un principio de igualdad expreso más las garantías jurisdiccionales (en la línea de la Constitución de 1931), y por lo demás constitucionaliza los derechos pero desde la sorpresiva recepción de la superioridad reconocida como valores (vinculable al iusnaturalismo filosófico) inviolables e inherentes a la persona y superiores a la propia Constitución y al Tribunal Constitucional. Mi opinión es que se trata de un sincretismo rico e inteligente; la mejor protección sin duda de los derechos del ciudadano en el constitucionalismo español. Y curiosamente puede encontrarse para colmo en la Constitución de 1978 -siempre en la dirección de ese sincretismo- incluso una referencia a un Derecho superior al natural (o un superderecho hace tanto tiempo olvidado), y superior en definitiva a -o delimitador, conceptuador o validador de- los derechos naturales o "inviolables" e "inherentes". Sucede así cuando, como colofón, los "derechos fundamentales y libertades -públicas, a tenor del título de la sección primera del capítulo II del título I- constitucionales" quedan sujetos a un orden universal. El artículo 10.2 reza:

"Las normas relativas a los derechos fundamentales y a las libertades que la Constitución reconoce, se interpretarán de conformidad con la Declaración Universal de Derechos Humanos y los tratados y acuerdos internacionales sobre las mismas materias ratificados por España".

Luego el precepto positiva en la Declaración Universal de Derechos Humanos y en el Derecho internacional un -si se me permite la expresión- nuevo Derecho supranatural. Elevada entonces la razón conceptual hacia ese cielo, no es de extrañar la resurrección de la disputa para la dominación de su espacio: un Derecho divino de la Cristiandad europea (al que apuntaría la nueva mixtura conservadora católicoprotestante en su hipotético revival neocatecumenal) contra el origen mismo de la razón constitucional o sea la Moral Universal (del sólo a la postre excepcionalmente abrazado Libertinaje filosófico). 